\title{
O PROCESSO DE APRENDIZAGEM SIGNIFICATIVA DE CONCEITOS EM AULAS DE EDUCAÇÃO FÍSICA DO ENSINO MÉDIO
}

\author{
THE MEANINGFUL LEARNING PROCESS OF CONCEPTS IN HIGH SCHOOL \\ PHYSICAL EDUCATION CLASSES
}

Cristiano José Martins de Miranda ${ }^{1}$, Rachel Belmont ${ }^{2}$, Evelyse dos Santos Lemos ${ }^{3}$

Recebido: Fevereiro/2021 Aprovado: Abril/2021

\begin{abstract}
Resumo: Considerando que o processo de ensino-aprendizagem na Educação Física escolar deve integrar pensamentos, sentimentos e ações para favorecer a aprendizagem com significado, o objetivo desse estudo foi compreender o processo de aprendizagem significativa de conceitos em aulas de Educação Física do ensino médio. A pesquisa, do tipo intervenção pedagógica, assumiu como principal referencial teórico a Teoria da Aprendizagem Significativa. Um plano de ensino cujo tema eram as respostas do sistema cardiovascular ao exercício físico, considerando sua relação com a Saúde e com a Aptidão Física, foi desenvolvido. Registros foram obtidos por meio da gravação das aulas, anotações em diário de campo e atividades escritas. Os dados foram analisados e discutidos considerando o aluno, o conteúdo, o professor, o contexto e a avaliação. Foi possível identificar evolução no conhecimento dos alunos, embora, para níveis abaixo do desejado. Acreditamos que a aprendizagem dos alunos tenha sido negativamente influenciada pelo contexto. Por outro lado, o professor parece ter interferido positivamente no processo. Os alunos demonstraram motivação para aprender, mas valorizavam muito o conteúdo prático. Parte deles apresentou resistência às tarefas teóricas e à avaliação escrita.
\end{abstract}

Palavras-chave: ensino, prática corporal, sistema cardiovascular.

\begin{abstract}
Considering that the teaching-learning process in school physical education should integrate thoughts, feelings, and actions to foster meaningful learning, this study aimed to understand the conceptual meaningful learning process in high school physical education classes. This pedagogical intervention research used the meaningful learning theory as the main theoretical framework. A teaching plan with concepts of the cardiovascular response to exercise and its relationship with health and physical aptitude was developed. Records were obtained through the audio recording class, field notes, and students' written activities. The data were analyzed and discussed focusing on students, content, teacher, context, and evaluation. It was possible to identify improvements in the students' knowledge, although below the desired level. We believe that students' learning may have been negatively influenced by the context. On the other hand, the teacher seems to have positively interfered in the learning process. The students showed motivation to learn, however, they highly valued the practical content. Also, part of them showed resistance to do theoretical activities and written evaluation.
\end{abstract}

Keywords: Teaching, body practices, cardiovascular system.

1 (ID) https://orcid.org/0000-0001-6236-4780 - Doutor em Ciências pela Fiocruz. Rua Carvalho Alvim, 406, ap. 501, Andaraí, CEP 20510-095, Rio de janeiro, RJ, Brasil. E-mail: cristianojmmiranda@gmail.com

2 (iD https://orcid.orq/0000-0003-2611-6661 - Doutora em Ciências pela Fiocruz. Docente no Programa de Pós-graduação Stricto Sensu em Ensino em Biociências e Saúde da Fiocruz. Av. Brasil, 4365. Pavilhão Arthur Neiva-EBS. Rio de Janeiro -RJ. CEP: 21040-360. E-mail: rachelsbelmont@gmail.com

3 (iD https://orcid.org/0000-0003-1024-5290 - Doutora em Ensino de Ciências pela Universidade de Burgos/Espanha. Docente no Programa de Pós-graduação Stricto Sensu em Ensino em Biociências e Saúde da Fiocruz. Av. Brasil, 4365. Pavilhão Arthur Neiva-EBS. Rio de Janeiro -RJ. CEP: 21040-360. E-mail: evelyse@ioc.fiocruz.br 


\section{Introdução}

Este estudo é fruto da nossa (1) preocupação com o elevado nível de sedentarismo na população adolescente e adulta brasileira, apesar da participação em aulas de Educação Física Escolar (EFE) durante a educação básica; (2) insatisfação com a falta de preparo dos estudantes para tomarem decisões responsáveis sobre questões referentes às práticas corporais e (3) crença em que a aprendizagem de aspectos referentes à prática corporal, sob diversas perspectivas, contribui para a formação integral do estudante. Com esta perspectiva, repensamos o ensino de $\mathrm{EFE}$, considerando a necessidade de integrar à dimensão procedimental, em geral predominante nas aulas desta componente curricular, as dimensões atitudinal e conceitual. Considerando este propósito, defendemos a potencialidade da Teoria da Aprendizagem Significativa (TAS) (AUSUBEL, 2003) para subsidiar o ensino da EFE. Além disso, assumimos que as situações de ensino, que se realizam na relação triádica entre professor, alunos e conhecimento (GOWIN, 1981), devem ser planejadas tomando como referência o conhecimento prévio dos aprendizes visando possibilitar a integração do seu pensamento, sentimento e ação para, efetivamente, terem o potencial de favorecer a aprendizagem significativa (NOVAK, 2010). Ademais, acreditamos que a aprendizagem com significado, quando efetivada no contexto da EFE, capacita os sujeitos à tomada de decisões responsáveis sobre questões referentes às próprias práticas corporais. Cientes do pequeno número de pesquisas relacionando a TAS, o ensino e a aprendizagem da EFE, desenvolvemos este estudo com o objetivo de compreender o processo de aprendizagem de conceitos efetivado em aulas de EFE planejadas e desenvolvidas à luz da TAS. Entendendo que esta compreensão não é uma tarefa fácil, considerando todas as idiossincrasias envolvidas, decidimos estudar este processo em situação de ensino regular. Realizamos duas intervenções pedagógicas, em dois anos letivos consecutivos, orientadas por um plano de ensino cujo tema central eram as respostas do sistema cardiovascular ao exercício físico, considerando sua relação com a Saúde e com a aptidão física. Coerente com a TAS, sempre comprometidas com a função da disciplina na educação básica e com atenção nos alunos e contexto envolvidos, as aulas, alternando atividades práticas e teóricas, envolveram dinâmicas variadas, todas valorizando a participação e expressão dos alunos e, assim, a avaliação processual deles e do próprio ensino. Apesar da diversidade de dados construídos, neste momento, nos deteremos a apresentar e discutir (1) o nível de conhecimento expresso pelos alunos e (2) as percepções dos alunos, do professor e dos pesquisadores sobre o processo de ensino e de aprendizagem realizado.

\section{A organização do ensino de Educação Física à luz da Teoria da Aprendizagem Significativa e do Construtivismo Humano}

A disciplina EFE surgiu nas escolas brasileiras no final do século XIX, por meio de aulas de Gymnástica (ARANTES, 2008), essencialmente práticas e pautadas nos hábitos de higiene e saúde. Tais aulas valorizavam o desenvolvimento físico e moral a partir do exercício (DARIDO; SANCHES NETO, 2014). Com o avanço dos estudos, surgiram novas concepções sobre a função 
da EFE na escola que culminaram na coexistência de várias abordagens que, em comum, defendem a necessidade de atenção ao aluno e seu contexto sociocultural. Esta pluralidade, nem sempre percebida, reflete a necessidade de se repensar o cotidiano desta disciplina no contexto escolar e o papel a ela determinado nas propostas curriculares mais recentes.

Há pouco tempo, o Ministério da Educação brasileiro apresentou a Base Nacional Comum Curricular (BNCC) (BRASIL, 2018), documento que apresenta a EFE como "o componente curricular que tematiza as práticas corporais em suas diversas formas de codificação e significação social, entendidas como manifestações das possibilidades expressivas dos sujeitos e patrimônio cultural da humanidade." (BRASIL, 2018, p. 213).

Além disso, é argumento desta proposta que:

Cada prática corporal propicia ao sujeito o acesso a uma dimensão de conhecimentos e de experiências aos quais ele não teria de outro modo. A vivência da prática é uma forma de gerar um tipo de conhecimento muito particular e insubstituivel e, para que ela seja significativa, é preciso problematizar, desnaturalizar e evidenciar a multiplicidade de sentidos e significados que os grupos sociais conferem às diferentes manifestações da cultura corporal de movimento. (BRASIL, 2018, p. 214).

No tocante à EFE, a BNCC, ainda que não enfatize a concepção de aprendizagem que a orienta, ou poderia orientar, apresenta princípios coerentes com os pressupostos da TAS. Ou seja, ao defender a tematização das práticas corporais com vistas à compreensão pessoal em seus diferentes sentidos e significados, a proposta curricular reflete, ainda que implicitamente, a ideia de que os significados são pessoais, contextuais e construídos a partir da interação construtiva do sentir, pensar e agir (NOVAK, 2010), uma das premissas básicas da Teoria original (AUSUBEL, 2003), amplamente difundida por Novak (1993) ao propor o Construtivismo Humano.

O processo de ensino e de aprendizagem, como enfatiza Lemos (2011), ganhou uma nova perspectiva quando David Ausubel, em 1963, propôs o conceito de aprendizagem significativa e, com ele, a TAS. A Teoria está baseada na proposição de que a aquisição e a retenção de conhecimentos são o produto de um processo (mentalmente) ativo, integrador e interativo entre o material de ensino e as ideias relevantes previamente presentes na estrutura cognitiva do aprendiz (AUSUBEL, 2003). Ausubel considerava que a aprendizagem pode acontecer de forma mecânica ou significativa, ainda que estas não sejam dicotômicas. Na aprendizagem por memorização ou mecânica o novo conhecimento não modifica (ou modifica pouco) a estrutura cognitiva do aluno, se relacionando com ela de forma arbitrária e literal. Embora a memorização de fatos, números, símbolos etc. possa ser útil em determinadas situações, o aluno terá dificuldade para utilizar as ideias memorizadas na interpretação e solução de problemas em contextos diferentes dos que the são familiares. No mesmo continuum, a aprendizagem significativa ocorre quando o novo conhecimento se relaciona com a estrutura cognitiva do aluno de forma não arbitrária (não aleatória) e substantiva (não literal), modificando-a. Desta maneira, quando ocorre a aprendizagem significativa, o novo conhecimento fica disponível para uso futuro, inclusive em situações diferentes da de aprendizagem. 
Tendo em conta estes aspectos, concordamos com Lemos (2011) quando diz que o ensino não é a atividade fim do processo educativo, mas o meio pelo qual a aprendizagem significativa do aluno é favorecida e sua qualidade não depende somente de estratégias didáticas específicas, mas, fundamentalmente, da concepção de aprendizagem que orienta as decisões do professor e do aluno ao longo do seu processo. Cabe ao professor assumir o compromisso de favorecer a aprendizagem significativa pautando suas ações na ideia de que o significado está nas pessoas e não nos materiais (MOREIRA, 2012). Por isso, além de o ensino enfocar os significados e buscar garantir que o aluno pense com e sobre o conhecimento em diferentes momentos e situações, é essencial que ele assuma sua responsabilidade no processo educativo, percebendo a informação, interpretando-a e exteriorizando os significados que está captando e representando mentalmente.

De acordo com Novak (2010), os processos de ensino sofrem a influência do professor, do aluno, do conhecimento, do contexto e da avaliação e a natureza da integração desses cinco elementos tem influência direta no tipo de aprendizagem que se dará, seja mais mecânica ou mais significativa. Além disso, na concepção deste autor, a educação pode ser vista como um conjunto de experiências que integrando aspectos cognitivos, afetivos e motores conduzem ao empoderamento humano. Nesta perspectiva, Novak (2013) defende que quando alguma forma de performance é requerida numa tarefa de aprendizagem, torna-se imperativo que o aprendiz procure - ativamente - integrar o pensamento, o sentimento e a ação. Esta integração tende a possibilitar a formação dos significados mais consolidados, robustos, como vemos nos experts em qualquer campo.

Desta forma, ao pensarmos em um plano de ensino de EFE, por meio do qual as aulas possam ter potencial para favorecer a aprendizagem significativa, os conteúdos devem ser definidos e, como ponto inicial, orientar a elaboração da sequência didática. Com esta perspectiva, sempre respeitando o estágio maturacional, os conhecimentos prévios e perfil socioeconômico dos estudantes, bem como o tempo e perfil institucional disponível para as aulas, definem-se as estratégias e recursos de ensino. Neste contexto, propomos que o plano de ensino de EFE seja organizado em unidades ou sessões, cujo número de aulas é determinado pelos objetivos específicos, pela realidade da situação de ensino, de acordo com os interesses e capacidades dos alunos, com a organização das escolas e com a formação do professor. Importa também considerar que é mais produtivo ensinar poucos conceitos em contextos variados, prioritariamente os estruturantes (Gagliardi, 1986), do que muitos em poucas situações.

Considerando o exposto, as sessões (aula ou sequência de aulas com um objetivo comum) devem apresentar uma dinâmica que possibilite a integração do pensamento, do sentimento e da ação em relação à prática corporal tematizada. Assim, orientadas por esta premissa, propomos que as sessões sejam organizadas em três momentos: 1) Proposição e discussão sobre uma situação problema; 2) vivência de práticas corporais: atividades, relacionadas ao problema apresentado, que, enquanto estimulam o desenvolvimento de capacidades e habilidades motoras, possibilitam aos estudantes a sensação e a percepção das suas respostas em aspectos biológicos, psicológicos e socioculturais e; 3 ) síntese: retoma a discussão visando a consolidação 
dos sentidos e significados captados durante a sessão por meio da reconciliação integrativa e da diferenciação progressiva. Dessa forma, os alunos interagem entre si e o professor interage com os alunos perguntando, ouvindo e comentando respostas, orientando a reflexão sobre as ideias iniciais, as sensações vivenciadas durante as atividades e os significados que pretende que sejam aprendidos.

Nessa conjuntura, a avaliação permeia todo o processo, influenciando a decisão sobre o quê, como, onde e em que tempo ensinar. Na expectativa que os alunos assumam seu papel no processo, o professor deve permanecer atento às evidências de aprendizagem significativa (AUSUBEL, 2003) que suas falas podem expressar, observando o uso das ideias ensinadas nas falas, práticas e trabalhos dos estudantes.

\section{Metodologia}

A investigação realizada, do tipo intervenção pedagógica (DAMIANI et al., 2013) com abordagem qualitativa, aprovada pelo Comitê de Ética em Pesquisa da Fundação Oswaldo Cruz (parecer: 1.503.063), assumiu a TAS (AUSUBEL, 2003; NOVAK, 2010; GOWIN, 1981) como principal referencial teórico. Seu contexto foram as aulas regulares de EFE do ensino médio em uma escola pública do Estado do Rio de Janeiro.

O professor regente da disciplina, primeiro autor deste artigo, docente na escola havia 14 anos, desenvolveu em suas turmas regulares, com alunos voluntários, nos anos letivos de 2016 (Estudo 1) e 2017 (Estudo 2), um processo de ensino cujo tema central eram as respostas do sistema cardiovascular ao exercício físico, considerando sua relação com a Saúde e com a aptidão física. Em publicação anterior, apresentamos uma discussão mais aprofundada sobre o plano de ensino planejado (MIRANDA; BELMONT; LEMOS, 2016). Aqui, nos limitaremos a apresentar um quadro com os problemas que pretendíamos abordar a cada aula (Quadro 1).

Quadro 1 - Problemas a serem abordados

\begin{tabular}{|c|c|}
\hline Aula & Problemas \\
\hline 1 & $\begin{array}{l}\text { Pré-teste - Quais são as respostas do sistema cardiovascular ao exercício físico? Quais são as diferenças entre o indivíduo } \\
\text { em repouso e em atividade física? Quais são as diferenças entre o indivíduo fisicamente ativo e o sedentário? }\end{array}$ \\
\hline 2 & O que é ser saudável? Quais as necessidades para isto? \\
\hline 3 & Qual é o estado de aptidão física dos alunos? \\
\hline 4 & Qual é a relação entre a atividade física, aptidão física e a saúde? \\
\hline 5 & $\begin{array}{l}\text { Toda atividade física provoca a mesma resposta em relação à aptidão física e a saúde? Por que os atletas das diferentes } \\
\text { modalidades apresentam características corporais diferentes? }\end{array}$ \\
\hline 6 & Quais são as diferenças entre o repouso e a atividade física? \\
\hline 7 & Como se dá a circulação sanguínea no corpo humano? Como o oxigênio chega às células musculares no corpo humano? \\
\hline 8 & Qual é o estado de aptidão física dos alunos? Há diferença em relação ao estado inicial? \\
\hline 9 & Quais são os valores esperados de Frequência Cardíaca no repouso e no esforço máximo? \\
\hline 10 & Como e por que a Frequência Cardíaca é utilizada para o controle da intensidade do exercício? \\
\hline 11 & Quais são os valores esperados de Pressão Arterial no repouso e no esforço? Como aferir a Pressão Arterial? \\
\hline 12 & \\
\hline 13 & Qual é o comportamento da PA e da Frequência Cardíaca durante o exercício? Existe diferença entre exercícios? \\
\hline 14 & \\
\hline
\end{tabular}




\begin{tabular}{|c|c|}
\hline Aula & Problemas \\
\hline 15 & Qual é o comportamento da Pressão Arterial e da Frequência Cardíaca durante o exercício? Existe diferença entre sujeitos? \\
\hline 16 & Como é feito o controle da Frequência Cardíaca e da Pressão Arterial durante o exercício físico? \\
\hline 17 & $\begin{array}{r}\text { Quais são as respostas crônicas do sistema cardiovascular ao exercício? Por que os exercícios físicos são indicados para a } \\
\text { prevenção e tratamento de doenças do sistema cardiovascular? }\end{array}$ \\
\hline 18 & Qual é o estado de aptidão física dos alunos? Há diferença em relação aos estados anteriores? \\
\hline 19 & $\begin{array}{r}\text { Pós-teste - Quais são as respostas do sistema cardiovascular ao exercício físico? Quais são as diferenças entre o indivíduo } \\
\text { em repouso e em atividade física? Quais são as diferenças entre o indivíduo fisicamente ativo e o sedentário? }\end{array}$ \\
\hline
\end{tabular}

Fonte: os autores

No Estudo 1, realizado no ano letivo de 2016, devido à greve dos professores, ocupação reivindicatória dos alunos das instalações escolares e Jogos Olímpicos ${ }^{1}$, o número de aulas realizadas foi menor do que o planejado. Por isso, de 19 aulas previstas, apenas 10 foram realizadas, impossibilitando o desenvolvimento de parte do plano de ensino. Esses problemas refletiram no ano letivo de 2017 e demandou replanejamento com agrupamento de algumas aulas (em amarelo, Quadro 2) para que todo o conteúdo planejado pudesse ser ensinado no Estudo 2. Assim, o Quadro 2 apresenta o calendário e as aulas ministradas.

\section{Quadro 2 - Calendário, aulas e registros realizados}

\begin{tabular}{|c|c|c|c|c|c|c|c|c|c|c|c|c|c|c|c|c|c|}
\hline Estudo & Aula & 1 & 2 & 3 & 4 & 5 & 6 & 7 & 8 & 9 & 10 & 11 & 12 & 13 & 14 & 15 & \\
\hline \multirow{2}{*}{$\begin{array}{c}1 \\
(2016)\end{array}$} & data & $\begin{array}{l}01 \\
\text { set }\end{array}$ & $\begin{array}{l}08 \\
\text { set }\end{array}$ & $\begin{array}{l}15 \\
\text { set }\end{array}$ & $\begin{array}{l}22 \\
\text { set }\end{array}$ & $\begin{array}{l}29 \\
\text { set }\end{array}$ & $\begin{array}{l}06 \\
\text { out }\end{array}$ & $\begin{array}{c}13 \\
\text { out }\end{array}$ & $\begin{array}{c}03 \\
\text { nov }\end{array}$ & $\begin{array}{c}17 \\
\text { nov }\end{array}$ & $\begin{array}{c}01 \\
\text { dez }\end{array}$ & & & & & & \\
\hline & aula do plano & 1 & 2 & 3 & 4 & 5 & 6 & 7 & $9 / 10$ & 11 & AV & & & & & & \\
\hline \multirow{2}{*}{$\begin{array}{c}2 \\
(2017)\end{array}$} & data & $\begin{array}{c}09 \\
\text { jun }\end{array}$ & $\begin{array}{l}30 \\
\text { jun }\end{array}$ & $\begin{array}{l}07 \\
\text { jul }\end{array}$ & $\begin{array}{c}18 \\
\text { ago }\end{array}$ & $\begin{array}{c}25 \\
\text { ago } \\
\end{array}$ & $\begin{array}{l}01 \\
\text { set }\end{array}$ & $\begin{array}{l}15 \\
\text { set }\end{array}$ & $\begin{array}{l}22 \\
\text { set }\end{array}$ & $\begin{array}{l}29 \\
\text { set }\end{array}$ & $\begin{array}{l}06 \\
\text { out }\end{array}$ & $\begin{array}{l}20 \\
\text { out }\end{array}$ & $\begin{array}{l}27 \\
\text { out }\end{array}$ & $\begin{array}{c}10 \\
\text { nov }\end{array}$ & $\begin{array}{c}17 \\
\text { nov }\end{array}$ & $\begin{array}{c}24 \\
\text { nov }\end{array}$ & $\begin{array}{c}16 \\
\text { mar }\end{array}$ \\
\hline & aula do plano & 1 & & 2 & $3 / 4 / 5$ & 6 & 7 & $9 / 10$ & 11 & 12 & 14 & 13 & AV & 16 & $16 / 17$ & AV & \\
\hline
\end{tabular}

Fonte: os autores

No Estudo 1, participaram 28 alunos do 1ํ, 2ㅇ e 3ㅇan ano do ensino médio, nove do sexo feminino e 19 do sexo masculino. No Estudo 2, a turma contou com 16 alunos do sexo masculino, estudantes do $2^{\circ}$ ano do ensino médio. Todos foram identificados por meio de códigos para assegurar o anonimato. A idade dos participantes variou entre 15 e 18 anos ( $\bar{X}=16,5)$ e todos optaram pela modalidade "Ginástica de Condicionamento Físico". Na unidade escolar, lócus da pesquisa, as turmas de Educação Física do Ensino Médio podem ser compostas por estudantes do 1 음 ao 3 o ano, procedentes dos diferentes cursos técnicos oferecidos em duas das escolas da unidade. Além disso, o aluno escolhe sua turma de EFE de acordo com o conteúdo das aulas: dança, ginástica, esportes ou lutas.

Devido à natureza do nosso problema de investigação, os registros utilizados foram variados e coletados ao longo de toda a intervenção. Foram realizadas gravação em áudio das aulas, anotações em diário de campo, registros de postagem em rede social e de trabalhos e testes escritos dos alunos.

Os trabalhos e testes escritos dos alunos consistiram em: (a) pré-teste e pós-teste análogo - questionário realizado antes e após o desenvolvimento da intervenção; (b) esquema

\footnotetext{
${ }^{1}$ Em 2016, a Cidade do Rio de Janeiro sediou os Jogos Olímpicos. Por questões logísticas, devido a estar localizada próximo a área de competições, a unidade escolar ficou fechada de 13 de julho a 28 de agosto.
} 
do conceito Saúde - desenhado pelos estudantes como tarefa após a segunda aula; (c) pós-teste modificado - carta escrita pelos estudantes para um amigo fictício contando o que haviam aprendido durante as aulas de Educação Física e criticando o processo de ensino e (d) pós-teste 2 - carta escrita para um professor fictício na qual o estudante deveria contar como havia sido a disciplina, explicar o que havia aprendido, mencionar quais seriam suas dúvidas e o que ainda gostaria de aprender além de reclamar do que não gostou e pedir para continuar o que foi bom.

O Quadro 3 apresenta a correlação entre o instrumento utilizado e as variáveis das quais seus registros poderiam conter indicativos, sendo potencialmente avaliadas. Além disso, é mostrado também o momento do Plano de ensino no qual o instrumento foi aplicado.

Quadro 3 - correlação entre o instrumento e a variável potencialmente avaliada

\begin{tabular}{|c|c|c|c|c|c|c|c|}
\hline \multicolumn{3}{|r|}{ Variáveis } & Pré-teste & \begin{tabular}{|c|} 
Esquema do \\
conceito Saúde
\end{tabular} & $\begin{array}{l}\text { Pós-teste } \\
\text { modificado }\end{array}$ & $\begin{array}{l}\text { Pós-teste } \\
\text { análogo }\end{array}$ & Pós-teste 2 \\
\hline \multirow{8}{*}{ 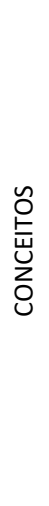 } & & Conceito de saúde & A & A & A & A & A \\
\hline & \multicolumn{2}{|c|}{ Exercício físico $X$ aptidão física $X$ saúde } & A & A & A & A & A \\
\hline & \multicolumn{2}{|c|}{$\begin{array}{c}\text { Especificidade do exercício físico X resposta } \\
\text { orgânica }\end{array}$} & A & & A & A & A \\
\hline & \multicolumn{2}{|r|}{ Resposta aguda ao exercício } & A & & $A$ & $A$ & $A$ \\
\hline & \multicolumn{2}{|c|}{$\begin{array}{l}\text { Papel do sistema cardiovascular no } \\
\text { transporte de } \mathrm{O}_{2} \text { e } \mathrm{CO}_{2}\end{array}$} & A & & A & A & A \\
\hline & \multicolumn{2}{|c|}{ Frequência cardíaca $\mathrm{X}$ exercício físico } & A & & A & A & A \\
\hline & \multicolumn{2}{|c|}{ Pressão arterial X exercício físico } & A & & A & A & A \\
\hline & \multicolumn{2}{|r|}{ Resposta crônica ao exercício } & & & & 2 & 2 \\
\hline \multicolumn{3}{|c|}{ Percepções dos estudantes } & & & A & & A \\
\hline \multirow{2}{*}{\multicolumn{2}{|c|}{$\begin{array}{l}\text { Momento } \\
\text { da } \\
\text { aplicação }\end{array}$}} & Estudo 1 & Início & $\begin{array}{c}\text { Após a segunda } \\
\text { aula }\end{array}$ & Após a aula 11 & Após a aula 11 & $\begin{array}{c}2,5 \text { meses após } \\
\text { última aula }\end{array}$ \\
\hline & & Estudo 2 & Início & $\begin{array}{c}\text { Após a segunda } \\
\text { aula }\end{array}$ & Após a aula 13 & Após a aula 17 & $\begin{array}{c}3,5 \text { meses após } \\
\text { a última aula }\end{array}$ \\
\hline
\end{tabular}

Fonte: os autores $A$-ambos os estudos 2 -Estudo 2

Os registros foram analisados principalmente de forma qualitativa pela análise de conteúdo categorial de Bardin (2010), utilizando, especificamente, (1) o procedimento por caixas e (2) o procedimento por acervo. A análise categorial funciona por operações de desmembramento do texto em unidades, em categorias segundo reagrupamentos analógicos, tendo como possibilidade de categorização, a investigação dos temas, presentes nos discursos (BARDIN, 2010).

Para categorizar os registros referentes aos níveis de conhecimento dos estudantes a respeito dos conceitos ensinados aplicamos o "procedimento por caixa". Já, para categorizar os registros referentes às percepções dos estudantes acerca do processo de ensino, obtidos por meio do pós-teste modificado e do pós-teste 2 , empregamos o "procedimento por acervo".

Os critérios utilizados para a categorização das respostas dos alunos em relação aos conceitos ensinados encontrados no pré-teste, no pós-teste análogo, no pós-teste modificado e no esquema do conceito Saúde referentes aos níveis de conhecimento dos estudantes estão apresentados no Quadro 4. Neste quadro, as linhas se referem aos conceitos e proposições 
trabalhadas e as colunas aos critérios utilizados para a categorização dos registros encontrados ao longo do ano letivo. Podemos observar que cada conceito trabalhado foi categorizado em cinco níveis de conhecimento enumerados de 0 a 4 . Sendo 4 o mais completo.

Quadro 4 - critérios utilizados para a categorização dos temas encontrados no pré-teste, no pós-teste análogo, no pós-teste modificado e no esquema do conceito Saúde

\begin{tabular}{|c|c|c|c|c|c|}
\hline Conceitos & \multicolumn{5}{|c|}{ Critérios } \\
\hline Saúde & $\begin{array}{l}\text { Apresenta o } \\
\text { conceito } \\
\text { ampliado de } \\
\text { saúde }\end{array}$ & $\begin{array}{l}\text { Considera além } \\
\text { da componente } \\
\text { física }\end{array}$ & $\begin{array}{l}\text { Considera } \\
\text { apenas a } \\
\text { componente } \\
\text { física }\end{array}$ & Incorreto & Em branco \\
\hline $\begin{array}{l}\text { Exercício físico x } \\
\text { aptidão física x } \\
\text { saúde }\end{array}$ & $\begin{array}{l}\text { Explica a relação } \\
\text { corretamente }\end{array}$ & $\begin{array}{l}\text { Considera } \\
\text { aspectos } \\
\text { coadjuvantes ao } \\
\text { exercício físico }\end{array}$ & \begin{tabular}{|l|} 
Considera \\
apenas o \\
papel do \\
exercício físico
\end{tabular} & $\begin{array}{l}\text { Não relaciona a } \\
\text { saúde ao } \\
\text { exercício físico }\end{array}$ & Em branco \\
\hline $\begin{array}{l}\text { Especificidade do } \\
\text { exercício físico x } \\
\text { resposta orgânica }\end{array}$ & $\begin{array}{l}\text { Explica a relação } \\
\text { corretamente }\end{array}$ & $\begin{array}{l}\text { Relaciona } \\
\text { corretamente os } \\
\text { elementos }\end{array}$ & $\begin{array}{l}\text { Relaciona os } \\
\text { elementos de } \\
\text { forma } \\
\text { equivocada }\end{array}$ & $\begin{array}{l}\text { Não considera a } \\
\text { relação }\end{array}$ & Em branco \\
\hline $\begin{array}{l}\text { Respostas agudas } \\
\text { ao exercício } \\
\text { (repouso x } \\
\text { atividade física) }\end{array}$ & $\begin{array}{l}\text { Identifica mais } \\
\text { de } 2 \text { respostas } \\
\text { agudas ao } \\
\text { exercício físico }\end{array}$ & $\begin{array}{l}\text { Identifica } 2 \\
\text { respostas ao } \\
\text { exercício físico }\end{array}$ & $\begin{array}{l}\text { Identifica } 1 \\
\text { resposta ao } \\
\text { exercício físico }\end{array}$ & $\begin{array}{l}\text { Não identifica } \\
\text { as respostas ao } \\
\text { exercício físico }\end{array}$ & Em branco \\
\hline $\begin{array}{l}\text { Papel do sistema } \\
\text { cardiovascular no } \\
\text { transporte de } \mathrm{O}_{2} \text { e } \\
\mathrm{CO}_{2}\end{array}$ & $\begin{array}{l}\text { Explica o papel } \\
\text { do sistema } \\
\text { Cardiovascular } \\
\text { no transporte } \\
\text { de } \mathrm{O}_{2} \text { e } \mathrm{CO}_{2}\end{array}$ & \begin{tabular}{|l|} 
Cita \\
corretamente \\
alguns elementos \\
do sistema no \\
transporte
\end{tabular} & $\begin{array}{l}\text { Identifica que } \\
\text { o sistema } \\
\text { cardiovascular } \\
\text { atua no } \\
\text { transporte de } \\
\mathrm{O}_{2} \text { e } \mathrm{CO}_{2}\end{array}$ & $\begin{array}{l}\text { Não identifica o } \\
\text { papel do } \\
\text { sistema } \\
\text { cardiovascular } \\
\text { no transporte } \\
\text { de } \mathrm{O}_{2} \text { e } \mathrm{CO}_{2}\end{array}$ & Em branco \\
\hline $\begin{array}{l}\text { Frequência } \\
\text { cardíaca x exercício } \\
\text { físico }\end{array}$ & \begin{tabular}{|l} 
Explica \\
adequadamente \\
a relação entre \\
a FC e o \\
exercício físico
\end{tabular} & $\begin{array}{l}\text { Identifica } \\
\text { satisfatoriamente } \\
\text { a relação entre a } \\
\text { FC e o exercício } \\
\text { físico }\end{array}$ & \begin{tabular}{|l|} 
Identifica \\
parcialmente \\
a relação \\
entre a FC e o \\
exercício físico
\end{tabular} & $\begin{array}{l}\text { Não estabelece } \\
\text { relação entre a } \\
\text { FC e o exercício } \\
\text { físico }\end{array}$ & Em branco \\
\hline $\begin{array}{l}\text { Pressão arterial x } \\
\text { exercício físico }\end{array}$ & \begin{tabular}{|l} 
Explica \\
adequadamente \\
a relação entre \\
a PA e o \\
exercício físico
\end{tabular} & $\begin{array}{l}\text { Identifica } \\
\text { satisfatoriamente } \\
\text { a relação entre a } \\
\text { PA e o exercício } \\
\text { físico }\end{array}$ & \begin{tabular}{|l|} 
Identifica \\
parcialmente \\
a relação \\
entre a PA e o \\
exercício físico
\end{tabular} & $\begin{array}{l}\text { Não estabelece } \\
\text { relação entre a } \\
\text { PA e o exercício } \\
\text { físico }\end{array}$ & Em branco \\
\hline $\begin{array}{l}\text { Respostas crônicas } \\
\text { ao exercício físico }\end{array}$ & $\begin{array}{l}\text { Identifica as } \\
\text { respostas em } 3 \\
\text { ou mais dos } \\
\text { aspectos } \\
\text { citados. }\end{array}$ & $\begin{array}{l}\text { Identifica as } \\
\text { respostas em } 2 \\
\text { dos aspectos } \\
\text { citados }\end{array}$ & $\begin{array}{l}\text { Identifica as } \\
\text { respostas em } \\
\text { um dos } \\
\text { aspectos } \\
\text { citados }\end{array}$ & $\begin{array}{l}\text { Não identifica } \\
\text { as respostas ao } \\
\text { exercício físico }\end{array}$ & Em branco \\
\hline Categoria & Completo & Satisfatório & Incompleto & $\begin{array}{l}\text { Ausente ou } \\
\text { Incorreto }\end{array}$ & Em branco \\
\hline Nível/ enumeração & (4) & (3) & (2) & (1) & (0) \\
\hline
\end{tabular}

Fonte: os autores 
Buscando dados que permitissem acompanhar e comparar as diferentes turmas e participantes dos Estudos nos diferentes momentos da intervenção, enumeramos as categorias obtidas na análise de conteúdo, utilizamos a contagem dos registros obtidos e aplicamos testes estatísticos por meio do software de análise estatística IBM SPSS $22^{\circledR}$.

Visando a comparar o comportamento das variáveis nos registros obtidos por meio do pré-teste e do pós-teste análogo utilizamos o teste estatístico de Wilcoxon (GADDIS; GADDIS, 1990; BARROS; REIS, 2003).

Na análise do conteúdo do pós-teste 2, categorizamos a menção dos estudantes aos conceitos estudados em 4 categorias, a saber: Não cita (0) - esta categoria foi atribuída quando o estudante não citava o conceito; Cita (1) - esta categoria foi considerada quando o estudante citava o conceito sem dar nenhuma explicação sobre ele; Explica insuficientemente (2) - esta categoria foi atribuída quando o estudante explicava de forma insuficiente o conceito e Explica satisfatoriamente (3) - esta categoria foi atribuída quando o estudante explicava satisfatoriamente o conceito.

Diante desse quadro, para a compreensão do processo de aprendizagem dos alunos, analisamos os cinco elementos da educação (NOVAK, 2000): aluno, professor, conhecimento, contexto e a avaliação.

\section{Resultados e discussão}

Lembrando que o objetivo do estudo, antes de focar no quantitativo de erros e acertos, era compreender o processo de aprendizagem de conceitos em aulas de EFE planejadas e desenvolvidas à luz da TAS, adiantamos que os dados apontam que a aprendizagem diagnosticada se deu de forma gradual, pessoal e recursiva e que o processo sofreu influência dos cinco elementos da educação (NOVAK, 2000). Assim, sem desconsiderar a complexidade do fenômeno investigado, bem como a impossibilidade de total controle do conjunto de variáveis que nele interferem durante uma intervenção pedagógica, assumimos tais elementos como condutores de nossa análise. Ou seja, conforme preconiza a TAS (AUSUBEL, 2003), a discussão apresentada neste tópico terá como foco o aluno, o professor, o conhecimento, o contexto e a avaliação.

Em relação ao aluno, a pergunta central é se houve aprendizagem?

Os dados construídos, com base no Quadro 4, a partir dos registros do pré-teste, do esquema do conceito de saúde, do pós-teste análogo e do pós-teste modificado estão sintetizados na Tabela 1.

A partir desta tabela, construímos o Gráfico 1 que apresenta a frequência de casos nos níveis de conhecimento dos alunos em diferentes momentos da intervenção pedagógica, possibilitando a percepção da sua evolução gradual. Por meio dele, nós podemos, por exemplo, constatar que, em relação ao conceito Saúde, todos os alunos apresentavam no pré-teste conhecimento em nível incompleto ou acima e que no pós-teste a frequência de casos nos níveis satisfatório e completo aumentou. 
Tabela 1 - Categorização por nível de conhecimento no pré-teste, pós-teste análogo, pós-teste modificado e esquema de saúde, conforme critérios apresentados no Quadro 4

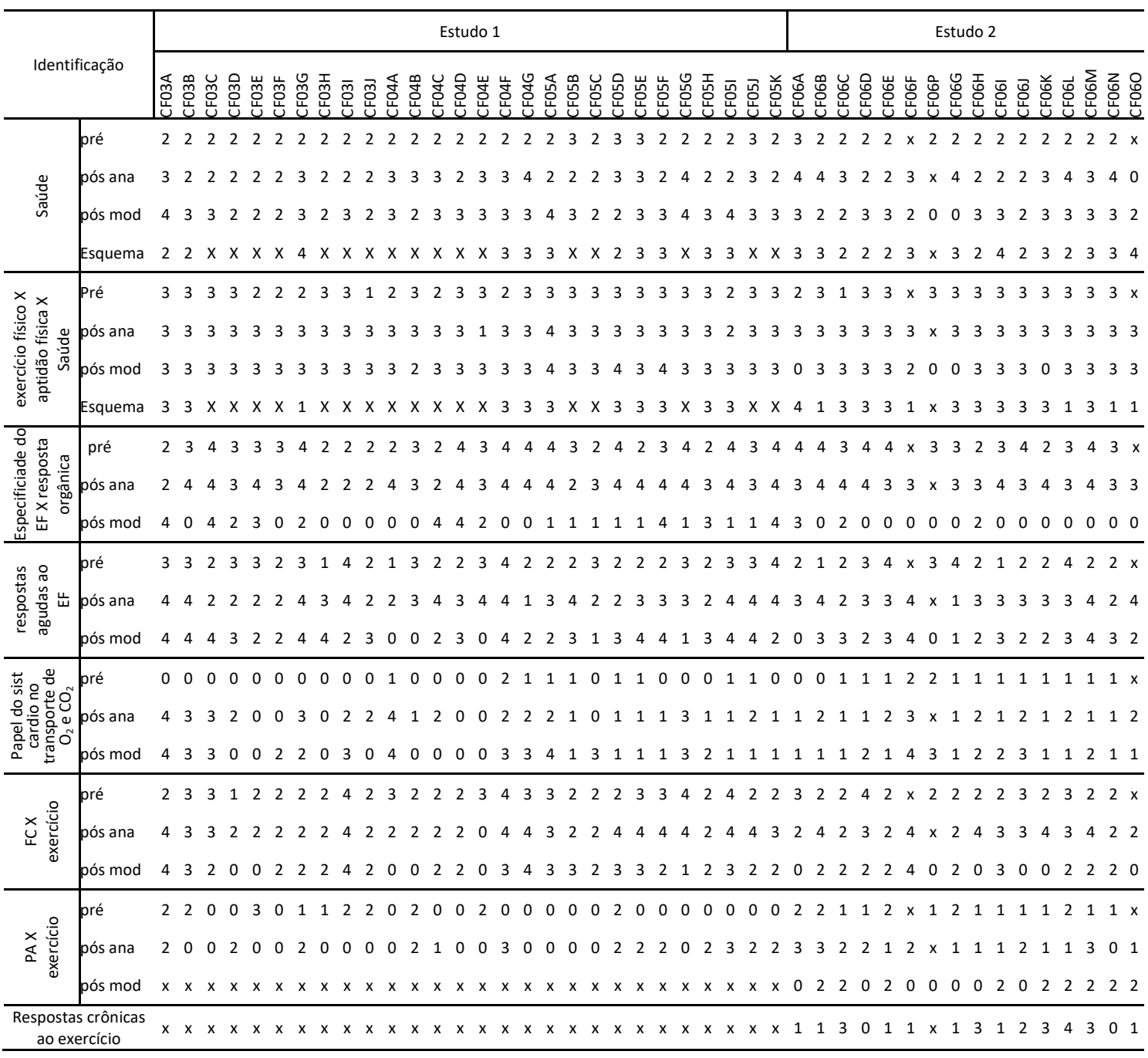

Fonte: os autores

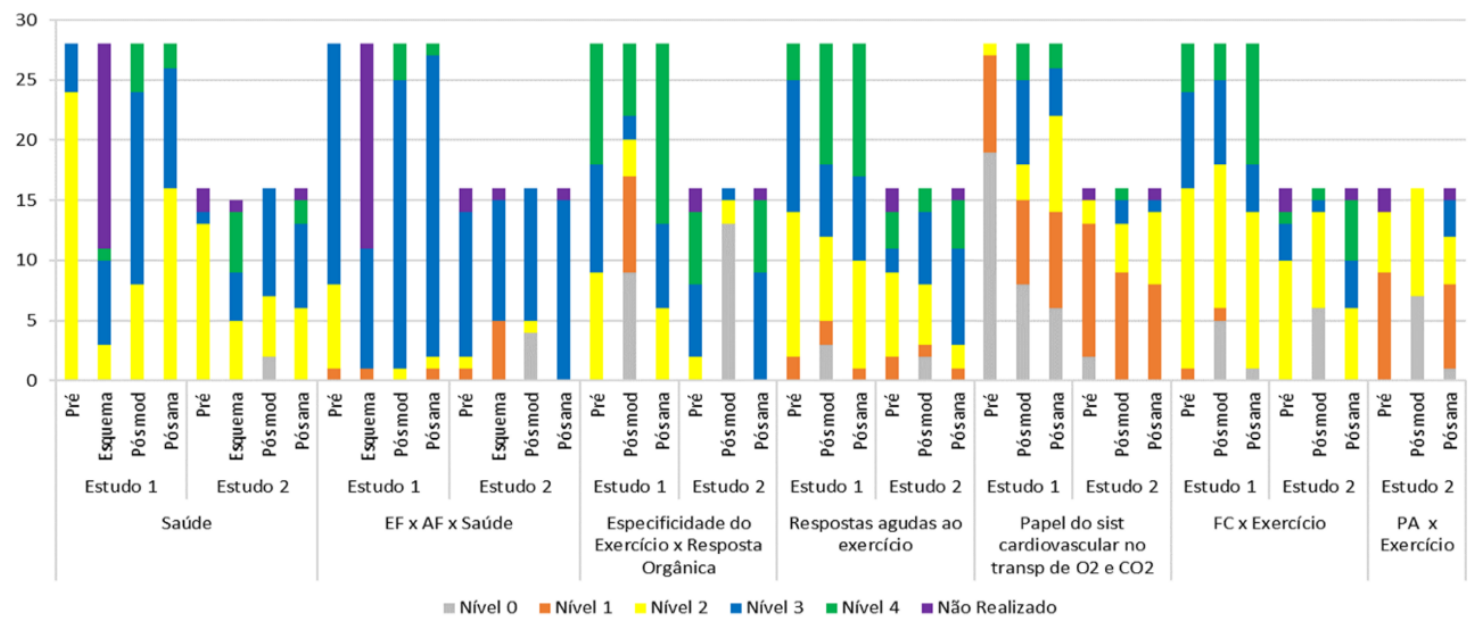

Gráfico 1 - Frequência de casos nos níveis de conhecimento no Pré-teste, Esquema do conceito de Saúde e Pós-testes modificado e análogo. (Fonte: os autores) 
Mesmo ciente do avanço, com o objetivo de verificar, com precisão estatística, a diferença entre o nível de conhecimento dos conceitos no início e no final da intervenção, realizamos o teste de Wilcoxon para comparar os resultados do pré-teste e do pós-teste análogo (Tabela 2). Esta análise mostrou que houve evolução no nível de conhecimento dos alunos em alguns dos conceitos ensinados $(p<0,05)$, mas não em todos. Além disso, considerando o conjunto dos alunos, a evolução se deu para nível abaixo do desejado, se focarmos o número de alunos que atingiram o nível completo de conhecimento.

Tabela 2 - Comparação dos níveis de conhecimento dos alunos entre o pré-teste e o pós-teste análogo

\begin{tabular}{|c|c|c|c|c|c|c|c|c|c|c|c|c|c|c|c|c|c|}
\hline \multirow{2}{*}{ Conceitos } & \multirow{2}{*}{ Estudo } & \multicolumn{6}{|c|}{ Níveis pré-teste } & \multicolumn{6}{|c|}{ Níveis pós-teste } & \multirow{2}{*}{ Pós<pré } & \multirow{2}{*}{ Pós>pré } & \multirow{2}{*}{ Pós=pré } & \multirow{2}{*}{$\begin{array}{l}\text { Wilcoxon } \\
\text { Asymp. Sig }\end{array}$} \\
\hline & & 0 & 1 & 2 & 3 & 4 & $x$ & 0 & 1 & 2 & 3 & 4 & $x$ & & & & \\
\hline \multirow{2}{*}{ Conceito de Saúde } & 1 & 0 & 0 & 24 & 4 & 0 & 0 & 0 & 0 & 16 & 10 & 2 & 0 & 1 & 9 & 18 & $0,013^{*}$ \\
\hline & 2 & 0 & 0 & 13 & 1 & 0 & 2 & 0 & 0 & 6 & 7 & 2 & 1 & 0 & 6 & 7 & $0,020 *$ \\
\hline \multirow{2}{*}{ EF x AF x Saúde } & 1 & 0 & 1 & 7 & 20 & 0 & 0 & 0 & 1 & 1 & 25 & 1 & 0 & 1 & 8 & 19 & 0,080 \\
\hline & 2 & 0 & 1 & 1 & 12 & 0 & 2 & 0 & 0 & 0 & 15 & 0 & 1 & 0 & 2 & 11 & 0,180 \\
\hline \multirow{2}{*}{$\begin{array}{l}\text { Especificidade do exercício } \\
\text { físico x Resposta orgânica }\end{array}$} & 1 & 0 & 0 & 9 & 9 & 10 & 0 & 0 & 0 & 6 & 7 & 15 & 0 & 1 & 7 & 20 & $0,033^{*}$ \\
\hline & 2 & 0 & 0 & 2 & 6 & 6 & 2 & 0 & 0 & 0 & 9 & 6 & 1 & 3 & 4 & 6 & 0,527 \\
\hline \multirow{2}{*}{$\begin{array}{c}\text { Respostas agudas ao } \\
\text { exercício }\end{array}$} & 1 & 0 & 2 & 12 & 11 & 3 & 0 & 0 & 9 & 7 & 7 & 11 & 0 & 4 & 14 & 6 & $0,012^{*}$ \\
\hline & 2 & 0 & 2 & 7 & 2 & 3 & 2 & 0 & 1 & 2 & 8 & 4 & 1 & 3 & 7 & 3 & 0,250 \\
\hline \multirow{2}{*}{$\begin{array}{l}\text { Papel do Sist cardiovascular } \\
\text { no transp de } \mathrm{O}_{2} \text { e } \mathrm{CO}_{2}\end{array}$} & 1 & 19 & 8 & 1 & 0 & 0 & 0 & 6 & 8 & 8 & 4 & 2 & 0 & 0 & 17 & 11 & $0,000 *$ \\
\hline & 2 & 2 & 11 & 2 & 0 & 0 & 1 & 0 & 8 & 6 & 1 & 0 & 1 & 0 & 7 & 7 & $0,011^{*}$ \\
\hline \multirow{2}{*}{ FC $x$ exercício } & 1 & 0 & 1 & 15 & 8 & 4 & 0 & 1 & 0 & 13 & 4 & 10 & 0 & 2 & 8 & 18 & 0,143 \\
\hline & 2 & 0 & 0 & 10 & 3 & 1 & 2 & 0 & 0 & 6 & 4 & 5 & 1 & 2 & 5 & 6 & 0,083 \\
\hline PA x exercício & 2 & 0 & 9 & 5 & 0 & 0 & 2 & 1 & 7 & 4 & 3 & 0 & 1 & 4 & 6 & 3 & 0,405 \\
\hline
\end{tabular}

Fonte: os autores

*diferença estatisticamente significativa $(p<0,05)$

Tomando como referência a premissa da TAS de que uma evidência de aprendizagem com significado é a capacidade de uso do conhecimento em novas situações e momentos, os alunos realizaram o pós-teste 2 dois meses e meio depois do final da intervenção no Estudo 1 e 3 meses e meio depois do final da intervenção no Estudo 2. Assim, devido a este intervalo de tempo e à natureza do instrumento, diferente dos anteriores, acreditávamos no seu potencial para revelar a aprendizagem significativa dos alunos. 0 Gráfico 2, no qual a cor da barra representa o conceito e seu comprimento a categoria, apresenta os níveis de classificação da menção dos conceitos pelos estudantes no pós-teste 2 . 0 ideal era que tivéssemos barras multicoloridas e o mais compridas possível. No entanto, não foi isso que observamos. Dentre os conceitos trabalhados, os mais citados foram sistema cardiovascular; pressão arterial e Saúde, porém, poucos foram explicados. 


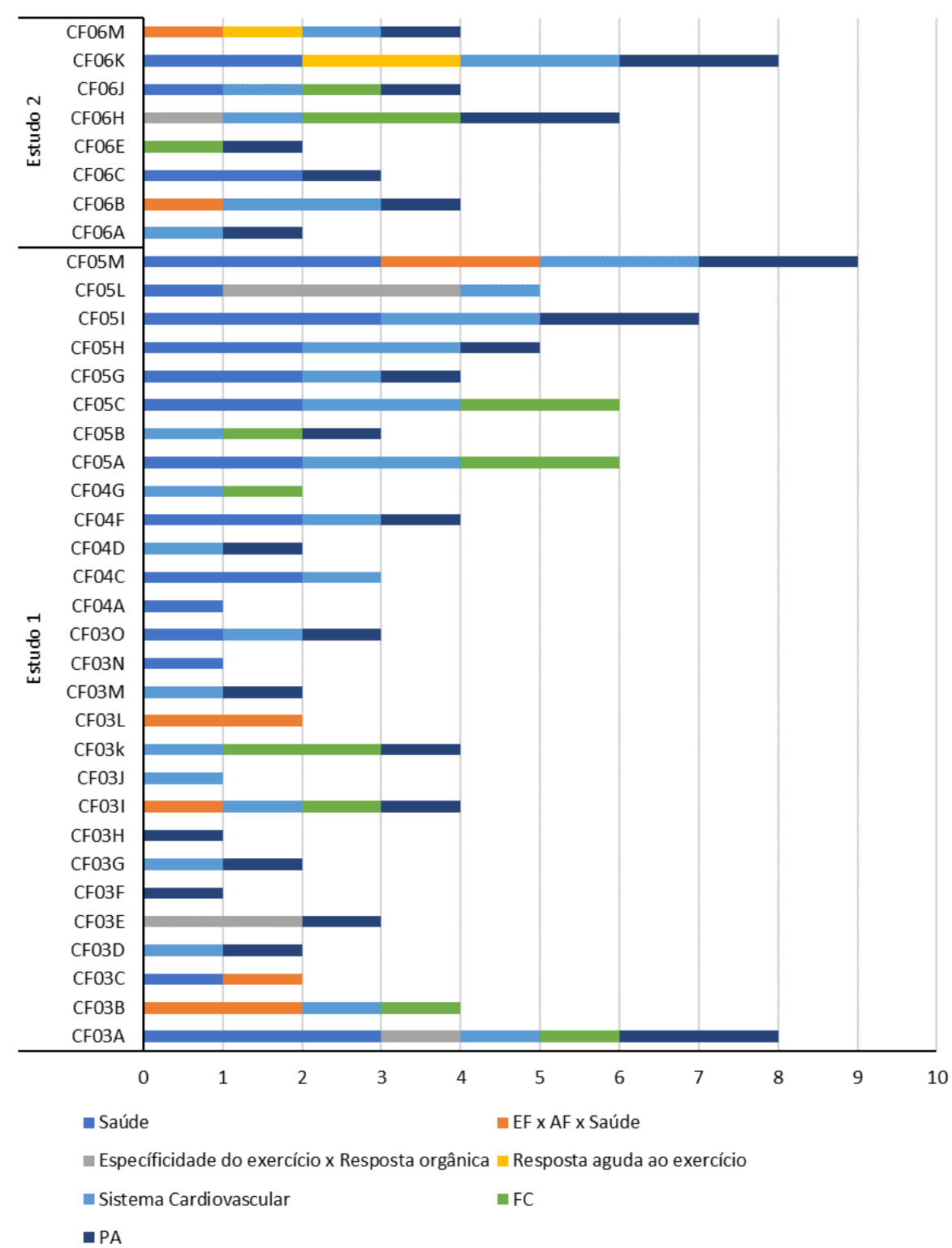

Obs. O comprimento da barra representa o nível de classificação da menção dos conceitos pelo aluno: (0) Não cita; (1) cita; (2) explica insuficientemente e (3) explica satisfatoriamente

Gráfico 2 - níveis de classificação da menção dos conceitos pelos estudantes no pós-teste 2. (Fonte: os autores)

Os dados apresentados comparando os níveis de conhecimento entre o pré-teste, o esquema do conceito de saúde, os pós-testes análogo e modificado explicitam evidências de captação de significado. Já os dados referentes ao pós-teste 2 mostram evidências de aprendizagem significativa. Esse princípio obedece ao pressuposto que a aprendizagem significativa é posterior a captação de significados e, além disso, é uma ação pessoal e intencional na qual o aprendiz escolhe relacionar a nova informação com os conhecimentos 
prévios já existentes na sua estrutura cognitiva (GOWIN, 1981). Mas, como desejávamos compreender o processo, o mais importante era saber o que determinou este resultado. Para tal fim, analisamos as percepções dos sujeitos envolvidos - alunos e professor - à luz da Teoria.

Conforme adiantado, o pós-teste modificado e o pós-teste 2 permitiram a apreensão das percepções dos alunos sobre o ensino.

No pós-teste modificado orientamos que o estudante revelasse suas expectativas no início do período letivo e que reclamasse do que estivesse sentindo falta. Respectivamente, 22 e 12 estudantes no Estudo 1 e 2 produziram textos que nos permitiram identificar os temas apresentados na Tabela 3.

Tabela 3 - Percepções dos estudantes sobre o ensino registradas no pós-teste modificado

\begin{tabular}{cc|cc}
\hline Estudo 1 & Estudo 2 & Temas \\
\hline Temas & $\begin{array}{c}\text { Alunos } \\
\text { (n=22) }\end{array}$ & $\begin{array}{c}\text { Alunos } \\
\text { (n = 12) }\end{array}$ \\
\hline Expectativa de prática & 15 & Reclamação por não jogar futebol o tempo todo/ expectativa de prática & 6 \\
Gosta das aulas & 10 & Aulas interessantes/ boas/ produtivas & 4 \\
Aprendizagem conceitual & 6 & Surpresa com as aulas/ modelo de aula diferente & 3 \\
Melhorar o condicionamento & 4 & Aprendendo coisas que não imaginava/ bom para o aprendizado & 3 \\
Perda do interesse & 3 & Não sente falta de nada & 2 \\
Excesso de teoria & 3 & Expectativa de poucas aulas por falta do professor \\
Sentir como o corpo reage & 2 & Ensino de coisas novas & Gostou da experiência \\
Expectativa de se tornar saudável & 1 & Adorou o conhecimento adquirido \\
Decepção & 1 & Tudo bem ensinado & 1 \\
Seguindo as dicas & 1 & Animado & 1 \\
& & Interesse, pois aprendeu sobre o corpo \\
& & Falta de costume de aula dentro de sala \\
\end{tabular}

Fonte: os autores

Podemos observar que: (1) em relação ao Estudo 1, a expectativa de prática foi citada 15 vezes, embora 10 alunos declararam ter gostado das aulas teórico-práticas. Por exemplo, o aluno CF05D disse: "Eu no início das aulas pensei que só faria atividades físicas, mas além disso eu ainda estou aprendendo sobre o funcionamento do corpo e conhecendo o meu melhor, então, não tenho do que reclamar" e, (2) em relação ao Estudo 2, o mais recorrente foi a menção à expectativa de atividade predominantemente prática nas aulas de EFE assim como à surpresa com o modelo de aulas e com o conteúdo que estavam aprendendo. Neste sentido, o aluno CF06D declarou: "Eu gostei da experiência e adorei o conhecimento que adquiri no processo. Acho que não sinto falta de nada, tudo está sendo passado quando se deve, e bem passado". Já, o aluno CF06N relatou:

Minhas expectativas no início do ano eram de praticar diversos esportes e não ter aula teórica. Agora vejo que está sendo ao contrário, que ao mesmo tempo que é bom para o meu aprendizado, confesso que se torna tedioso, mas acredito que essa minha afirmação seja por questão de costume pois nunca tive aula de Educação Física dentro de sala.

No pós-teste 2, pedimos para os alunos reclamarem do que não tinham gostado e solicitarem a continuidade do que foi bom. Assim, conseguimos registros com informações sobre suas percepções a respeito dos cinco elementos da educação. 
Em relação ao contexto, os alunos relataram influência das exigências do curso técnico; da preparação para o vestibular, da greve e da crise do Estado ${ }^{1}$ sobre o processo de ensino. Neste sentido, o estudante CfO3D lembrou-se da interferência da greve no andamento do plano de ensino: "A disciplina é muito boa, porém devido à greve não tivemos muitas aulas".

Analisando se o contexto social da sala de aula favoreceu a negociação e compartilhamento de significados, com base na observação do professor e anotações no diário de campo, consideramos que ele (professor) atuou neste sentido e que os alunos também mantiveram relacionamento amistoso e colaborativo, respeitando-se mutuamente.

Em relação ao contexto organizacional, consideramos que o tempo destinado às aulas de EFE e para o desenvolvimento do plano de ensino, tendo em vista os problemas enfrentados, influenciaram negativamente o processo. No entanto, a disponibilidade do material e do espaço físico foram positivos. Com respeito à organização das turmas, consideramos que a rede de ensino deveria rever o tratamento dado a disciplina, ainda com perfil promotor de prática de atividade física, priorizando sua componente procedimental.

Neste tocante, de acordo com Lemos (2007), as situações de ensino devem estar baseadas em objetivos definidos em função das suas características contextuais, formadas pela integração da natureza dos perfis dos sujeitos e do ambiente (considerando os diferentes níveis) no qual acontece.

Ademais, é notório o tratamento diferenciado que recebe a EFE pelos estudantes, professores e administradores escolares em relação a outras disciplinas cujos conteúdos predominam nos vestibulares brasileiros. A esse respeito, Mattos e Neira (2013) denunciam que as aulas de Educação Física não têm contado com a participação efetiva de parte dos alunos preocupados com sua preparação para o vestibular. Desvia-se, assim, o foco da Educação Básica para "exames" em detrimento da formação básica geral.

No que se refere ao conteúdo das aulas, grande parte dos alunos aprovou a dinâmica com integração dos conhecimentos práticos e teóricos, como podemos observar nos relatos dos alunos CF03F: "Bom, nossa Ed. Física era bem legal porque o nosso antigo professor não só nos ensinava a fazer os exercícios na prática, mas também nos ensinava como funciona o corpo humano quando nós estamos fazendo o exercício" e CF03E: "Não tenho o que reclamar do nosso último professor, pois as aulas sempre foram ótimas, tanto na parte teórica, quanto na prática, se possível gostaria que o senhor mantivesse o mesmo estilo de aula que o professor antigo."

Essa avaliação positiva, coerente com a ideia de que a integração do pensamento, do sentimento e da ação tende a possibilitar a formação dos significados mais consolidados, robustos (NOVAk, 2013), vai ao encontro de nossos objetivo e proposta para a disciplina.

\footnotetext{
${ }^{1}$ Nos dois anos letivos de investigação, o Estado do Rio de Janeiro atravessava um período de restrições orçamentárias, o que levou o governo a decretar estado de calamidade pública no âmbito da administração financeira. Decreto no 45692 de 17 de junho de 2016 do governador do Estado do Rio de Janeiro.
} 
Além disso, Pereira e Moreira (2005) argumentam que "[...] durante o ensino médio a Educação Física não deve voltar-se apenas para a prática, mas utilizar-se de conhecimentos teóricos sobre o movimento humano e o esporte ou de problemas de ordem social, política, emocional, psíquica e física, criando situações-problema que o próprio aluno deverá resolver." (p. 122).

No entanto, esta correlação entre teoria e prática também foi avaliada negativamente por sete participantes do Estudo 1, como o aluno CF04G que afirmou:

A disciplina de Condicionamento físico foi totalmente diferente do que eu esperava, achei que seria muito mais prático do que teórico e isso foi de certa forma frustrante, pois quando escolhi essa disciplina não esperava ter que ficar fazendo trabalhos teóricos. [...], nessa matéria teve muita pergunta e poucas respostas, tudo tem que explicar o porquê e isso é extremamente chato, sinceramente, eu preferia ficar correndo e fazendo exercícios físicos do que ficar fazendo trabalhinhos, gostaria de ter mais aulas práticas.

Neste aspecto, alguns alunos ora teciam comentários positivos, ora negativos, o que parece indicar que a avaliação negativa está mais relacionada ao estranhamento da dinâmica das aulas do que ao conteúdo em si. Este foi o caso, por exemplo, do aluno CF03J que disse:

Bom, não tenho muito a reclamar, o professor é um excelente professor e eu aprendi muitas coisas boas com ele, bastante coisa mesmo, quase tudo sobre corpo sobre circulação, artéria, coração, pulmão. Aprendi coisas que até eu mesmo não sabia que tinha no meu corpo kkkkk [...]eu gostaria mesmo é de ter mais aulas de Ed. Física mesmo, tipo ficar na quadra, correr, jogar bola, fazer exercícios, que também é muito importante, e tipo parar um pouco de ficar fazendo trabalhos em sala e apresentando palestras, fora isso está tudo show.

A apreciação dicotômica sobre o conteúdo trabalhado presente na afirmação de que aprendeu muita coisa boa, mas que gostaria mesmo é de ter tido mais "aulas de Educação Física mesmo" corroboram os argumentos de Lutz, Telles e Ferreira (2014) quando atribuem à resistência de parte dos alunos e de professores de outras disciplinas e até mesmo de alguns de Educação Física em aceitar alguns conteúdos e propostas metodológicas que fujam daquelas comumente utilizadas em décadas passadas, ao fato de que durante muitos anos a EFE e os seus conteúdos terem representado uma prática predominantemente voltada à aptidão física e ao rendimento esportivo. Ademais, segundo estes autores, desconstruir o imaginário do aluno que chega à aula pronto para jogar uma "pelada" é uma barreira a ser quebrada.

Ainda em relação ao conteúdo das aulas, obtivemos registros referentes à solicitação de atividades práticas pelos estudantes. Neste aspecto, a análise revelou que todos os alunos valorizavam as atividades práticas, o que reflete seu interesse pela dimensão procedimental do conteúdo. Neste sentido, a fala do aluno CF05C representa os alunos que solicitaram o aumento da prática: "Ano passado aprendi muito sobre saúde, aulas teóricas foram fundamentais para me aprofundar no assunto. [...]A única coisa que eu acrescentaria são as aulas na quadra, acho que deveríamos ter mais." Na mesma linha, o aluno CF03K solicitou a realização de bastantes 
atividades físicas: "[...] que o senhor consiga nos passar todo seu conhecimento e que nós possamos realizar bastantes atividades físicas para sermos pessoas mais saudáveis."

Refletindo à luz da TAS, é possível perceber que, ainda que de modo não consciente, os alunos reconhecem a importância da interação com o conhecimento de diferentes maneiras. Com esta perspectiva, os alunos CF04A e CF05M, respectivamente, solicitaram a manutenção do trabalho: "O ritmo da matéria está bom, tendo um bom número de aulas teóricas e práticas." e "Não tenho nenhuma reclamação e peço para que o senhor continue com os exercícios em quadra, pois foi bom e nós saíamos do sedentarismo." No entanto, confirmando o valor dado a dimensão procedimental do conteúdo, alguns alunos solicitaram a realização de mais atividades práticas e menos teoria, como foi o caso do CF03D: "Porém acho que suas aulas poderiam ter menos trabalhos teóricos e mais aulas práticas".

A solicitação dos estudantes para a manutenção e aumento das atividades práticas vai ao encontro da preocupação de Betti e Zuliani (2002) sobre o risco das aulas de EFE se tornarem um mero discurso sobre a prática. Segundo os referidos autores, "[...] a Educação Física não pode transformar-se num discurso sobre a cultura corporal de movimento, sob pena de perder a riqueza de sua especificidade, mas deve constituir-se como uma ação pedagógica com aquela cultura" (p. 75).

Ainda que sejam muitas as variáveis que, combinadas, nos permitem avaliar o material de ensino potencialmente significativo, em relação ao conteúdo, avaliamos que foi potencialmente significativo visto que apresentava significado lógico e que os aprendizes possuíam conhecimento prévio para a aprendizagem significativa de conceitos referentes ao material de ensino, com base no resultado do pré-teste que realizamos (com exceção dos conceitos da relação pressão arterial $\mathrm{X}$ exercício físico e do papel do sistema cardiovascular no transporte de $\mathrm{O}_{2}$ e $\mathrm{CO}_{2}$ ). Além disso, consideramos que a natureza do conteúdo (em conjunto com os recursos e estratégias utilizados), possibilitou a integração do pensamento, do sentimento e da ação.

Quanto aos alunos, os dados indicam que a grande parte gostou das aulas até solicitando outros conteúdos, como a aluna CF03I que disse: “[...] além de todas essas coisas que eu aprendi, também gostaria de aprender mais detalhadamente como o consumo excessivo de alimentos com muitas calorias e o sedentarismo prejudicam o corpo, pois eu só como besteira e sou muito sedentária, e gostaria de saber também como funciona o metabolismo."

Contudo, o estudante CF03C reclamou do comportamento da turma em certas ocasiões impedindo que ele prestasse atenção no professor: "[...] o que eu não gostava tanto era do comportamento da minha turma em certas ocasiões, principalmente quando acabava os exercícios, talvez pela turma estar cansada ou algo do tipo, não dava para prestar tanta atenção no professor."

Já o estudante CFO3B condicionou o interesse nas aulas ao aumento das atividades práticas: "E a segunda sugestão seria um aumento nas aulas práticas, para que os alunos tenham um maior interesse em praticar atividades físicas." 
Ausubel (2003) apresenta a intenção como uma condição precursora das disposições mentais que orientam o aprendiz para a natureza e exigências da tarefa de aprendizagem e para iniciar a operação da disposição de aprendizagem apropriada. Além disso, o referido autor argumenta que para a aprendizagem ser significativa o aprendiz deve apresentar disposição para relacionar o material a ser aprendido de forma não arbitrária e não literal à sua estrutura cognitiva, o que exige sua atuação ativa. É essa disposição mental que prepara o aprendiz para o esforço, para a atenção, concentração e para a repetição (AUSUBEL, 2003).

Neste aspecto, Mattos e Neira (2013) apontam que o conteúdo deve adequar-se ao aluno e enfatiza que o professor ao se manter rígido em conteúdos desinteressantes aos alunos, termina em afastá-los da disciplina.

Nossa avaliação sobre o comportamento dos alunos no processo de ensino e de aprendizagem foi realizada considerando se apresentavam disposição para aprender. Para isso, utilizamos a assiduidade e a realização das tarefas passadas como indicativos. Em relação a assiduidade, a maioria dos alunos faltou pouco às aulas, apesar de um grupo ter faltado muito. Em relação à realização das tarefas, grande parte dos alunos realizou um número abaixo do desejado.

No que se refere a atuação do professor, alguns estudantes solicitaram a manutenção do tipo de aula realizada, apontando como aspectos positivos a interatividade, o dinamismo das aulas e a explicação com exemplos, como foi o caso dos alunos CF03L que disse: "As aulas de educação física (condicionamento físico) foram muito boas e interativas, por conta da comunicação entre todos e muito mais."; do aluno CF03F: "Não tenho nada a reclamar, gostava muito da dinâmica como o professor trabalhava." e do aluno CF05C: "Espero que o novo professor continue explicando com exemplos em sala (como aprendemos a medir a frequência cardíaca), deixa a aula mais interessante."

Como mencionamos, o plano de ensino desenvolvido compreendia situações de ensino baseadas na relação triádica entre professor, alunos e conhecimento, que partiam do conhecimento prévio dos alunos e possibilitavam a integração do seu pensamento, sentimento e ação. Neste tocante, segundo Mattos e Neira (2013, p. 31), “[...] a ênfase na autonomia condiciona a opção por uma proposta de trabalho que considere a atividade do aluno na construção de seus próprios conhecimentos, valorize suas experiências, seus conhecimentos prévios e a interação professor-aluno e aluno-aluno [...]" Além disso, na concepção destes autores, coerente com a TAS, cada aluno é considerado sujeito de seu processo de aprendizagem, enquanto o professor é o mediador da interação dos alunos com os objetos do conhecimento.

Ainda em relação à atuação do professor, alguns estudantes solicitaram a continuidade da atenção ao aluno, do interesse pelo seu aprendizado e fizeram referência ao engajamento do professor. A esse respeito, o aluno CF03C disse: "Seria ótimo que o senhor continue com as coisas boas do antigo professor, sendo atento com a condição dos alunos durante as atividades e antes das atividades, se tem como ter aula e entre tantas coisas..."; o aluno CF05L afirmou: "Não tenho reclamações a fazer, algo que deve continuar é o interesse pelo aluno, e pelo 
aprendizado do mesmo." e o aluno CF04F considerou: "De todas as aulas de Educação Física que eu já tive, a de Condicionamento Físico foi a que eu considerei mais substancial, com um professor mais engajado e exigente que qualquer outro."

A esse respeito, Moreira (2012) comenta que a facilitação da aprendizagem significativa depende muito mais de uma nova postura docente, de uma nova diretriz escolar, do que de novas metodologias, mesmo as modernas tecnologias de informação e comunicação.

No que concerne à avalição, alguns alunos solicitaram "alívio" devido ao "elevado" número de trabalhos e avaliações que realizam. Assim como, houve demonstração de insatisfação com o método de avaliação com provas e com a prova escrita realizada (pós-teste análogo). Neste sentido, o estudante CF03K solicitou que fosse levado em consideração o fato de estarem cursando um curso técnico e, além disso, estarem realizando cursos de preparação para os vestibulares:

Como pode ver, realizamos um monte de atividades, mas por fim, peço-lhe que alivie um pouco a turma de segundo, pois no ano letivo de 2016, para nós, está sendo muito conturbado, já que o número de matérias aumentou e consequentemente o número de trabalhos e avaliações também; outro fator expressivo é que fazemos um ensino técnico concomitante ao médio, o que necessita mais disponibilidade. Alguns alunos, como eu, sentiu a necessidade de entrar em um curso preparatório para ingressar em universidades públicas ou academias militares no turno da noite, já que estudamos em período integral. Tal fato deixa-nos sem tempo e exige uma dedicação especial. Espero que entenda o meu ponto de vista e do restante da turma que passa por essa mesma situação. (CFO3K)

\section{Considerações finais}

O compromisso central do presente artigo é contribuir para a produção de conhecimento sobre como favorecer a aprendizagem de conceitos relacionados às práticas corporais na EFE, sem transformar suas aulas em um mero discurso sobre a prática, o que a afastaria de sua especificidade. Tal meta apoia-se no fato de que (1) o objeto de estudo da EFE - as práticas corporais - agrega as dimensões conceitual, atitudinal e procedimental e; (2) o ensino da (e sobre a) atividade física desvinculado da aprendizagem de conceitos não é suficiente para preparar os estudantes para tomarem decisões responsáveis sobre questões referentes às próprias práticas corporais durante e após a vida escolar e nem para o desenvolvimento de atitudes e valores positivos que possibilitem um estilo de vida ativo. Partindo do exposto e cientes do pequeno número de estudos que retratam o ensino nessa perspectiva, nos questionamos sobre como se dá o processo de aprendizagem significativa de conceitos das respostas agudas e crônicas do sistema cardiovascular ao exercício físico em aulas de EF do ensino médio?

Diante dos resultados expostos, construímos o esquema apresentado na Figura 1, representando a nossa compreensão do papel dos cinco elementos da educação (aluno, professor, contexto, conteúdo e avaliação) no processo de aprendizagem significativa de 
conceitos em aulas de EF no ensino médio. Nele consideramos a atuação dos cinco elementos da educação como determinantes recíprocos do processo de aprendizagem.

Figura 1 - Os cinco elementos da educação e a aprendizagem significativa de conceitos na Educação Física Escolar (Fonte: os autores)

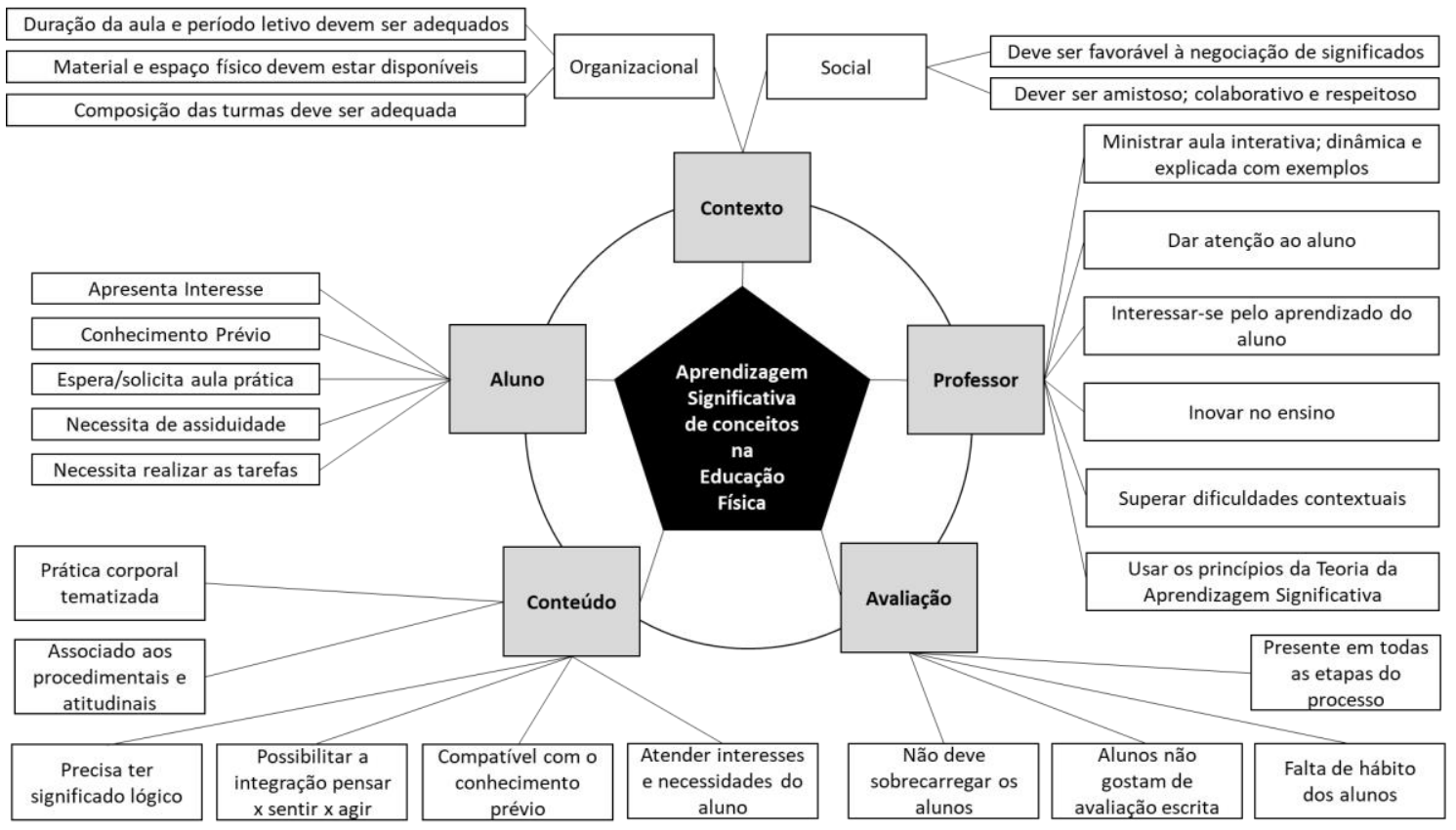

O contexto apresenta duas componentes: a organizacional e a social. Em relação à componente organizacional, inferimos que o tempo disponível para as aulas de EFE e a duração do período letivo devem ser adequados, assim como a disponibilidade de espaço físico e material tanto para aulas práticas quanto teóricas. Também apontamos como importante que as turmas sejam compostas adequadamente, visando a continuidade do processo de aprendizagem. $\mathrm{Na}$ unidade de ensino na qual os Estudos 1 e 2 foram realizados, as turmas de EFE eram compostas por alunos de diferentes anos de ensino, resquício, provavelmente, do período em que a EFE tinha status de atividade escolar. Hoje, como componente curricular, o ideal seria que o conhecimento sobre a disciplina fosse evoluindo e sendo consolidado ao longo do tempo, de ano de ensino para ano de ensino. Com esta perspectiva, não faz sentido que ao observarmos aulas de EFE dos diferentes anos de ensino vejamos as mesmas atividades, com os mesmos objetivos, como é comum. No tocante à sua componente social, compreendemos que o contexto deva ser favorável à negociação de significados, apresentando sujeitos (alunos e professor) que se relacionam de forma amistosa, colaborativa e respeitosa.

Quanto à atuação do professor no processo de aprendizagem significativa de conceitos na EFE, nosso entendimento é que ele deva (1) usar os princípios da TAS; (2) ministrar aulas interativas, dinâmicas e explicadas com exemplos; (3) dar atenção ao aluno; (4) inovar no ensino; (5) interessar-se pelo aprendizado do aluno e, (6) superar dificuldades contextuais.

No que diz respeito aos alunos, corresponsáveis pelo processo de aprendizagem, constatamos que apresentam interesse em aprender conceitos relativos ao corpo em movimento, mas esperam e solicitam que as aulas tenham predominantemente componentes 
práticos. Além disso, inferimos que para que os alunos aprendam os conceitos com significado precisam de conhecimento prévio, frequentar às aulas com assiduidade e realizar as tarefas propostas.

O conteúdo conceitual a ser aprendido na EFE é a prática corporal tematizada, e deve estar associado aos conteúdos procedimentais e atitudinais da disciplina. Além disso, precisa ter significado lógico, possibilitar a integração entre o sentimento, o pensamento e a ação, ser compatível com o conhecimento prévio dos alunos e atender seus interesses e necessidades.

Com relação à avaliação, apontamos que ela deve estar presente em todas as etapas do processo, mas alertamos que se deve tomar cuidado para que as tarefas propostas não acabem sobrecarregando os alunos, considerando seus compromissos com as outras disciplinas. Ademais, a falta de hábito dos alunos em realizar avaliação escrita na disciplina de EFE causa estranhamento e críticas por parte dos alunos que declaram não gostar de realizar avaliação escrita.

Com esta perspectiva, nossas sugestões são que: 1) os gestores da educação devem zelar pelo contexto para a realização das aulas de EFE, principalmente no tocante ao material, tempo e espaço físico disponível; 2) a unidade de ensino deve modificar seu tratamento à disciplina de EFE em relação à formação das turmas e a integração com as demais disciplinas, visando a possibilitar a organização sequencial dos conteúdos conceituais ao longo do processo formativo dos alunos e, 3) os professores devem cuidar para que as aulas de EFE no ensino médio sejam dinâmicas e interativas e seu conteúdo, abordado integrando o pensamento, o sentimento e a ação, seja oportuno à realidade contextual e pessoal dos estudantes, levando em conta seus interesses e necessidades.

A legitimação da EFE como disciplina escolar fundamental para a formação integral do cidadão requer a assimilação em sua base teórica de conhecimentos que orientem suas propostas de ensino visando à aprendizagem das dimensões conceitual, atitudinal e procedimental dos conteúdos. Por isso, a realização de estudos sobre o ensino da disciplina utilizando diferentes teorias explicativas da aprendizagem é importante para o desenvolvimento desse arcabouço teórico. Os dados que apresentamos, considerando o avanço no conhecimento dos alunos, mas muito mais pelas percepções dos alunos do processo de ensino e de aprendizagem realizado, indicam a potencialidade da utilização da TAS como base teórica para o ensino da EFE. No entanto, mais estudos devem ser realizados, principalmente com relação 1) a dosagem do tempo destinado à negociação de significados e a vivência das práticas corporais; 2) a intencionalidade do aluno para aprender e, 3) a avaliação da aprendizagem significativa da EFE.

\section{Referências}

ARANTES, Ana Cristina. A história da educação física escolar no Brasil. Efdeportes.com. ano 13, n. 24 - setembro de 2008. Disponível em: http://www.efdeportes.com/efd124/a-historia-daeducacao-fisica-escolar-no-brasil.htm. Acesso em: 25 abr. 2016. 
AUSUBEL, David P. Aquisição e retenção do conhecimento: uma perspectiva cognitiva. Lisboa: Ed. Platano, 2003.

BARDIN, Laurence. Análise de Conteúdo. Lisboa: Edições 70, 2010.

BETTI, Mauro, ZULIANI, Luiz Roberto. Educação Física Escolar: uma proposta de diretrizes pedagógicas. Revista Mackenzie de Educação Física e Esporte, v.1, n.1, p. 73-81, 2002. Disponível em: http://www.ceap.br/material/MAT25102010170018.pdf. Acesso em: 25 abr. 2016.

BARROS, Mauro V. G., REIS, Siqueira. Análise de dados em atividade física e saúde: demonstrando a utilização do SPSS. Londrina: Midiograf, 2003.

BRASIL. Ministério da Educação. Base Nacional Comum Curricular, 2018. Disponível em: http://basenacionalcomum.mec.gov.br/images/BNCC_EI_EF_110518_versaofinal_site.pdf. Acesso em 18 mar. 2021.

DAMIANI, Magda Floriana et al. Discutindo pesquisas do tipo intervenção pedagógica. Cadernos de Educação. v. 45, maio/ agosto 2013. Disponível em https://periodicos.ufpel.edu.br/ojs2/index.php/caduc/article/view/3822. Acesso em: 07 maio 2017.

DARIDO, Suraya Cristina; SANCHES NETO, Luiz. O contexto da Educação Física na Escola. In: DARIDO, Suraya Cristina; RANGEL, Irene Conceição Andrade (coordenação). Educação Física na escola: implicações para a prática pedagógica. 2. ed. Rio de Janeiro: Guanabara Koogan, 2014. p. 1-24.

GADDIS, Gary M.; GADDIS, Monica L. Introduction to Biostatistics: Part 5, Statistical Inference Techniques for Hypothesis Testing with Nonparametric Data. Annals of emergency medicine. v. 19, n. 9, september 1990. Disponível em: https://pubmed.ncbi.nlm.nih.gov/2203291/. Acesso em: 18 mar. 2021.

GAGLIARDI, R. Los Conceptos Estructurales en el Aprendizaje por Investigacion. Enseñanza de las ciencias, v. 4, n.1, p. 30-35, 1986. Disponível em: https://ddd.uab.cat/pub/edlc/edlc_a1986v4n1/edlc_a1986v4n1p30.pdf. Acesso em: 18 mar. 2021.

GOWIN, Bob D. Educating. Ithaca: Cornell University Press, 1981.

LEMOS, Evelyse dos Santos. A teoria da aprendizagem significativa e sua relação com o ensino e com a pesquisa sobre o ensino. Indivisa, Boletin de Estudios e Investigación, n. 8, p. 111-118, 2007. Disponível em: http://www.if.ufrgs.br/asr/artigos/Artigo_ID17/v1_n3_a2011.pdf. Acesso em: 18 mar. 2021.

LEMOS, Evelyse dos Santos. A aprendizagem significativa: estratégias facilitadoras e Avaliação. Aprendizagem Significativa em Revista/Meaningful Learning Review - v.1, n.1, p. 25-35, 2011. Disponível em: <http://www.if.ufrgs.br/asr/artigos/Artigo_ID3/v1_n1_a2011.pdf >. Acesso em: 25 abr. 2016. 
LUTZ, T.; TELLES, S. C. C.; FERREIRA, M. S. Educação Física escolar: [ainda] incertezas e indefinições. Salusvita, v. 33, n. 2, p. 223-241, 2014. Disponível em: https://secure.unisagrado.edu.br/static/biblioteca/salusvita/salusvita_v33_n2_2014_art_06.p df. Acesso em: 18 mar. 2021.

MATTOS, Mauro Gomes de; NEIRA, Marcos Garcia. Educação Física na Adolescência: construindo o conhecimento na escola. 6. ed. São Paulo: Phorte, 2013.

MIRANDA, C. J. M.; BELMONT, R. S.; LEMOS, E. dos S. Planejando o ensino e a aprendizagem de conceitos em aulas de educação física escolar. Aprendizagem Significativa em Revista. v. 6, n. 1, 2016b. Disponível em: <http://www.if.ufrgs.br/asr/artigos/Artigo_ID94/v6_n1_a2016.pdf>. Acesso em: 16 out. 2017.

MOREIRA, M. A. Al final, qué és aprendizaje significativo? Revista Qurriculum, n. 25, p. 26-56, 2012.

https://lume.ufrgs.br/bitstream/handle/10183/96956/000900432.pdf?sequence=1\&isAllowed =y. Acesso em: 18 mar. 2021.

NOVAK, Joseph D. Human Constructivism: A unification of psychological and epistemological phenomena in meaning making. International Journal of Personal Construct Psychology. v.6, n. 2, p. 167-193, 1993. Disponível em: http://cmapspublic3.ihmc.us/rid=1GNLG695M-VKGWHNCNX/1993\%20Novak\%20Human\%20Constructivism\%20A\%20Unification\%20of\%20Psychologi. pdf. Acesso em: 18 mar. 2021.

NOVAK, Joseph D. Aprender, criar e utilizar o conhecimento: mapas conceituais como ferramentas de facilitação nas escolas empresas. Lisboa: Plátano, 2000.

NOVAK, Joseph D. Learning, Creating, and Using Knowledge: Concept Maps as Facilitative Tools in Schools and Corporations. 2. ed. New York: Routledge, 2010.

NOVAK, Joseph D. Empowering Learners and Educators. Journal for Educators, Teachers and Trainers, v. 4, n. 1, p. 14-24, 2013. Disponível em: https://jett.labosfor.com/article_976.html. Acesso em: 18 mar. 2021.

PEREIRA, Raquel Stoilov; MOREIRA, Evando Carlos. A participação dos alunos do ensino médio em aulas de educação física: algumas considerações. Revista da Educação Física/UEM, v. 16, n. 2, p. 121-127, $2005 . \quad$ Disponível em: http://www.periodicos.uem.br/ojs/index.php/RevEducFis/article/view/3381/2427. Acesso em: 12 abr. 2019. 